\title{
THE RED BONE MARROW IN HEART FAILURE
}

\author{
BY \\ J. P. SHILLINGFORD \\ From the Bernhard Baron Institute of Pathology, London Hospital, E.I
}

(RECEIVED FOR PUBLICATION, AUgUST 16, 1949)

It is generally accepted that the normal amount of red marrow in the femur of healthy male adults does not exceed a few flecks or patches in the upper end of the bone. In the female this appearance is not so consistent, and the haemopoietic marrow may occupy up to a half or two-thirds of the shaft without evidence of anaemia or excessive blood loss from menstruation, haemorrhoids, or other explanatory cause (Turnbull, 1934).

In the routine examination at necropsy of the femora of all patients, both male and female, occasional examples display a great increase in the amount of red marrow, unassociated with anaemia or other obvious cause. On further study it appeared that this increase was closely associated with certain types of heart failure. This paper describes the results of analysis of the naked eye description of the femoral bone marrow at necropsy of 200 selected subjects, including various types of heart failure, and normal controls.

Some of the specimens were examined personally ; for the rest it was necessary to consult the records of the Institute. In order to obviate discrepancies that might arise from variation in the observations of different reporters it was decided to use the reports of one pathologist (Dr. W. W. Woods) only.

For this analysis it was felt desirable first to separate males from females, and to subdivide these into smaller groups, representing the various types of heart disease associated with cardiac failure. Where possible, 20 cases of each group were studied (Table I).

TABLE I

\begin{tabular}{|c|c|c|c|}
\hline & & \multicolumn{2}{|c|}{ No. of Cases } \\
\hline & & Males & Females \\
\hline $\begin{array}{l}\text { Controls } \\
\text { Hypertension without cardiac failure } \\
\text { Hypertension with cardiac failure } \\
\text { Mitral stenosis with cardiac failure } \\
\text { Emphysema with cardiac failure } \\
\text { Aortic valve disease with cardiac failure }\end{array}$ & $\begin{array}{ll}\cdots & \cdots \\
\cdots & \cdots \\
\cdots & \cdots \\
\cdots & \cdots \\
\cdots & \cdots \\
& \cdots\end{array}$ & $\begin{array}{l}20 \\
20 \\
20 \\
20 \\
20 \\
16\end{array}$ & $\begin{array}{r}20 \\
20 \\
20 \\
20 \\
11 \\
0\end{array}$ \\
\hline
\end{tabular}




\section{Controls}

The records of the amount of red marrow found in the femora of 20 male and female patients were examined. The subjects were all over the age of 40 , the oldest being 73. Death was due either to accidental trauma or to surgical operation, and careful note was made of the clinical and pathological records to exclude any disease that might be responsible for a variation in the amount of haemopoietic marrow. Of the males, one had confluent red marrow in the upper part of the shaft, head, and neck, 13 showed a few flecks or patches in the upper part of the bone, while six were fatty throughout (Figs. 1 and 3). The female group, on the other hand, demonstrated the erratic increase of haemopoietic tissue described by Turnbull (1934); thus 12 showed confluent red

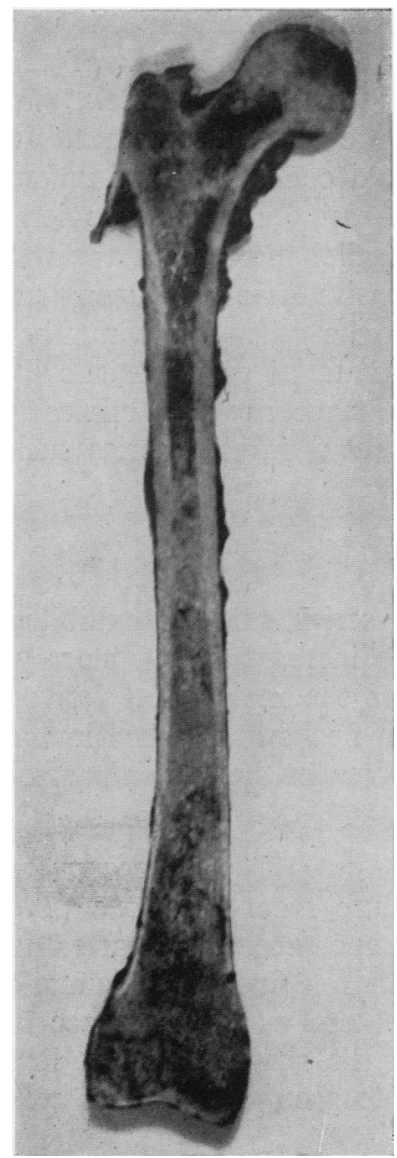

FIG. 1.-Right femur from a control male subject aged 61 , showing a few flecks and patches of red marrow in the upper part of the shaft, head, and neck.

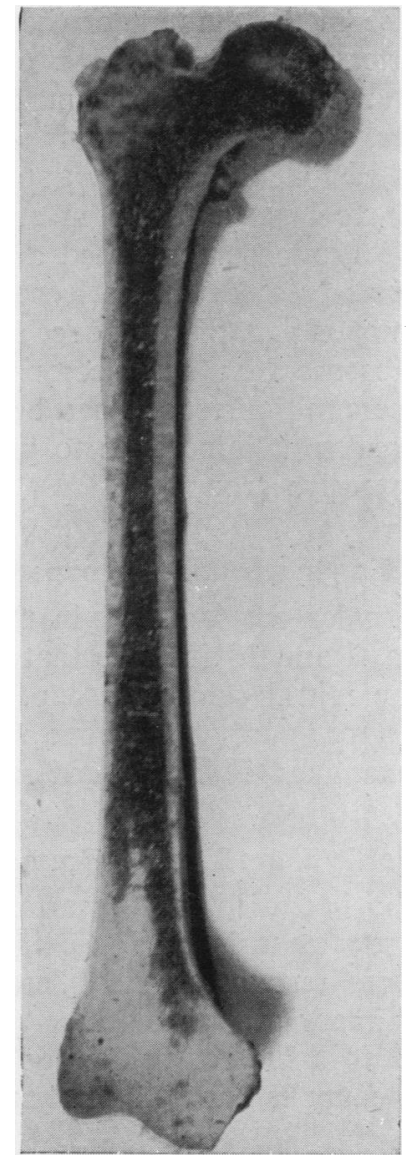

FIG. 2.-Right femur from a female subject, aged 63 , who died from hypertensive heart failure, showing great increase of red marrow. marrow in the upper part of the shaft, head, and neck of the bone, and the rest a few flecks and patches (Fig. 9).

\section{Hypertensive Group}

In subjects with essential hypertension, either benign or malignant, dying from causes other than heart failure (usually either cerebral haemorrhage or intercurrent acute illness), the amount of red haemopoietic marrow in the femora showed little variation from that in the control groups. The subjects studied were all over the age of 40 . The males showed a few flecks or patches in the head, neck, and upper part of the shaft (Fig. 4), and of the female femora three had areas of confluent red marrow and the rest flecks or patches in the greater part of the shaft, head, and neck (Fig. 10).

Where heart failure had been associated with the hypertension for periods 
of at least one month before death, both males and females showed a marked increase in the haemopoietic marrow. The criteria accepted for such heart failure were primarily clinical, and consisted of severe dyspnoea on exertion, or at rest, with corresponding physical signs of heart failure ; confirmation was provided by the organs at necropsy. Eighteen of the males showed confluent red marrow in the head, neck, and up to two-thirds of the length of the shaft of the femur (Fig. 5). The females showed a corresponding increase with confluent red marrow through the greater part of the bone in all cases except one which had many patches in the upper two-thirds (Fig. 11).

\section{Mitral Stenotic Group}

The examination of the bone marrow of this group showed that, although there was a significant increase in the amount of the haemopoietic tissue, it was not as great as in the hypertensive subjects (Figs. 6 and 12). Only six of the 20 male patients examined showed confluent red marrow in the head, neck, and shaft of the bone, 12 had flecks or patches, and two were fatty throughout. In some of these cases it was noted that the marrow appeared oedematous on naked eye examination; this may have been a factor in suppressing the haemopoietic response in these. The female group demonstrated a parallel increase in the red marrow which again was not as great as in the hypertensive cases. Fifteen had confluent red marrow in the upper part of the bone, and the other five a number of flecks and patches. The absence from our necropsy material of a statistically significant number of cases where mitral stenosis had been unaccompanied clinically by evidence of heart failure makes it impossible to present a parallel series such as was provided in the hypertensive group.

\section{Emphysematous Group}

Twenty males and 12 females are included in this series, and all exhibited cardiac failure clinically. Figs. 7 and 13 indicate that the increase of red marrow closely approaches that in the mitral stenotic group. Of the males, six showed confluent red marrow in the upper part of the bone with flecks or patches in the rest, and of the 12 females examined eight had red marrow in the upper part of the bone.

\section{Aortic Valve Disease Group}

Sixteen male subjects who had died from heart failure secondary to a pure aortic valve lesion, either aortic stenosis or aortic incompetence, are charted in Fig. 8. The aetiological factors responsible for these lesions include rheumatic heart disease, syphilis, and primary atheroma. In eight there was an increase in the red marrow, involving up to a half or two-thirds of the shaft. The rest had a few patches or flecks in the upper end. A comparable group of females was not obtained.

\section{Microscopical Histology}

In two of the cases of hypertensive heart failure showing this hyperplastic marrow macroscopically, the microscopic examination has yielded no information beyond an increased normoblastic proliferation. 


\section{Discussion}

A search of the literature has revealed no reference to naked eye observations on the red marrow in the various types of cardiac failure.

Weil (1901) drew attention to the polycythaemia of the peripheral blood in two children suffering from congenital heart disease, and noted that the marrow appeared very red and cellular.

Mackay (1907) confirmed these observations in an adult dying of congenital pulmonary stenosis. In antithesis he noted that in a middle-aged man dying from pulmonary emphysema, who was cyanosed in life without polycythaemia, the bone marrow at necropsy appeared normal. Parkes Weber (1913) found a decided erythroblastic reaction in the bone marrow of a woman aged 29 who, in life, had suffered from emphysema with cyanosis; at necropsy the greater part of the bone marrow of the humerus was of a dull, earthy-red colour.

Several observers have described polycythaemia without splenomegaly in association with hypertension. Geisböck (1904), in examining the blood of patients with increased blood pressure, found that the number of red cells was greatly increased, and his observations have been confirmed by Hess (1905), while Howard (1908) described one case of hypertension in association with polycythaemia but with no splenomegaly. Parkes Weber (1921) in a review of this condition of "polycythaemia hypertonica" quotes several cases, and considers it not uncommon. $\mathrm{He}$ believes that the polycythaemia is almost certainly secondary.

None of these observers has considered the influence of cardiac failure on the amount of polycythaemia, and, if our present observations on the amount of red marrow reflect what is happening in the peripheral blood, hypertension alone does not cause red marrow hyperplasia, but the superimposed heart failure is responsible. Groen and Godfried (1948) reported a series of cases of severe heart failure in which there was an increase in the number of circulating normoblasts in the blood, and concluded that this was a grave prognostic sign.

It is generally assumed that the stimulus to the haemopoietic system is low oxygen tension (Wintrobe, 1946); but in our series of cases the greatest hyperplasia was observed in the marrows of the hypertensive group of patients, who, on the whole, are less cyanosed and have a higher oxygen tension than the emphysematous or mitral stenotic groups. It seems likely that some factor other than anoxia is responsible for this variation. Dacie and White (1949) suggest that the actual flow of blood through the marrow is a factor which possibly affects erythropoiesis by controlling the delivery of erythrocytes into the circulation from the sinusoids, and perhaps even affects erythropoietic activity itself. Grant and Root (1947), working with dogs, observed an increased erythropoiesis that lasted for three weeks following loss of $30 \%$ of the blood volume, but the lowered oxygen tension and saturation of the bone marrow lasted from three to five hours only. Howarth and McMichael (1946) showed that hypertensive cardiac failure may be accompanied by increased peripheral resistance, which is diminished when the failure is relieved. Davis (1941) produced polycythaemia in rabbits by the administration of ephedrine ; it therefore seems possible that local vascular spasm may play a part in the increase in the haemopoietic marrow. 


\section{Summary}

Observations on the amount of red marrow found in the femur at necropsy in various types of heart disease have been recorded.

Essential hypertension alone has no effect on the haemopoietic marrow, but when cardiac failure has been present there is a marked increase in the red marrow.

This increase of red marrow, although present, does not occur to such an extent in heart failure associated with mitral stenosis or emphysema.

I wish to thank Professor Dorothy Russell for suggesting this investigation and for her help and encouragement in following it up ; Dr. W. W. Woods for his observations on necropsies; and Mr. John King for the photographs.

\section{REFERENCES}

Dacie, J. V., and White, J. C. (1949). J. clin. Path., $2,1$.

Davis, J. E. (1941). Amer. J. Physiol., 134, 219.

Geisböck, F. (1904). Ver. Kongr. f. Inn. Med. Wiesbaden, 21, 97.

Grant, W. C., and Root, W. S. (1947). Amer. J. Physiol., 150, 618.

Groen, J., and Godfried, E. G. (1948). Blood, 3, 1445.

Hess, O. (1905). Med. Klinik, Vienna, 1, 68.

Howard, T. (1908). J. Amer. med. Ass., 51, 1230.

Howarth, S., McMichael, J., and Sharpey-Schafer, E. P. (1946). Clin. Sci., 6, 41.

Mackey, L. G. J. (1907). Bgham. med. Rev., 10, 113.

Turnbull, H. M. (1934). The Anacmias. Ed. Vaughan, J. M. Oxford University Press. London. P. 11 .

Weber, F. P. (1913). Proc. R. Soc. Med., 6 (Sect. Med.), 83.

(1921). Polycythaemia, Erythrocytosis, and Erythraemia. Lewis. London.

Weil, E. (1901). C. R. Soc. Biol., Paris, 53, 713.

Wintrobe, M. M. (1946). Clinical Haematology. 2nd ed. London. Henry Kimpton. 
8
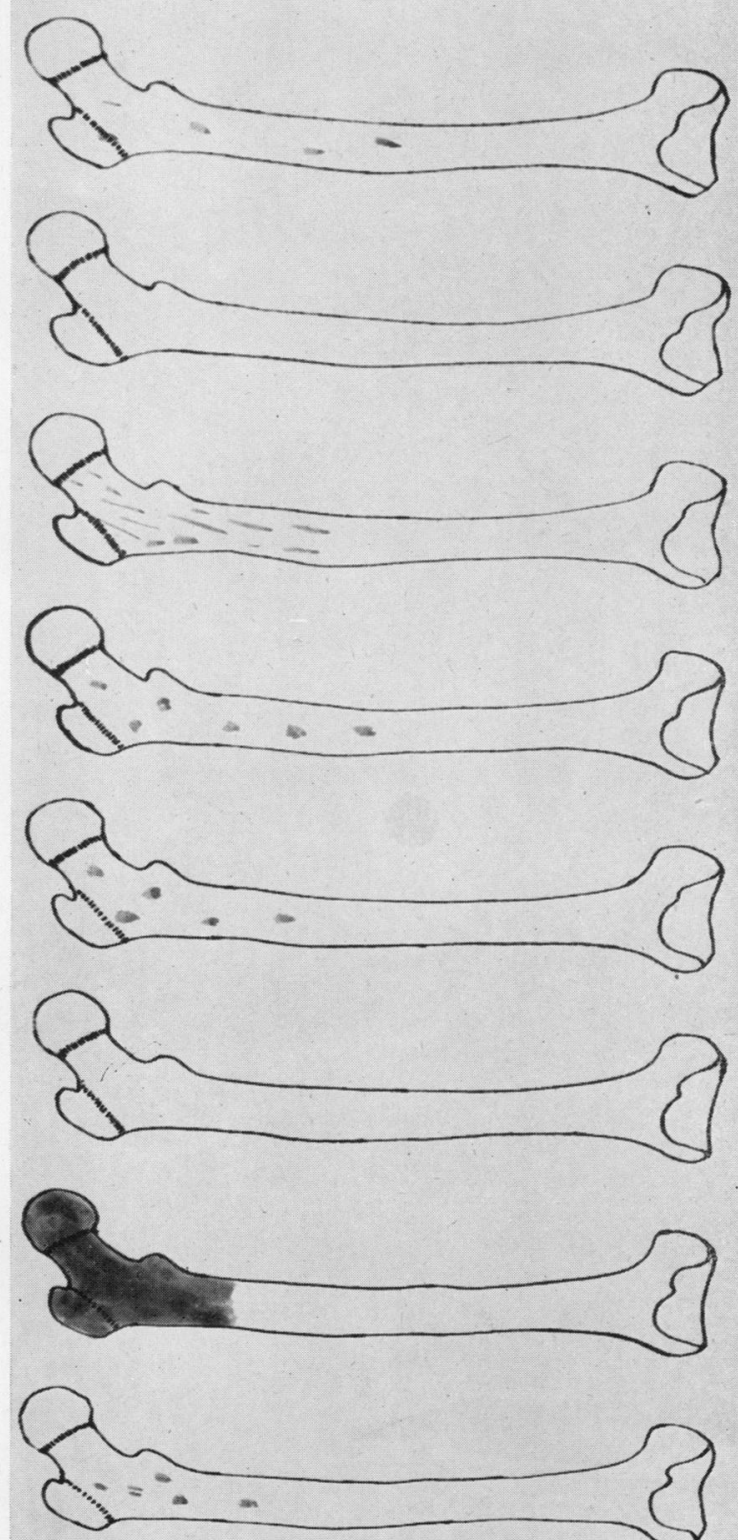

$n$
0
0
$\vdots$
0
0

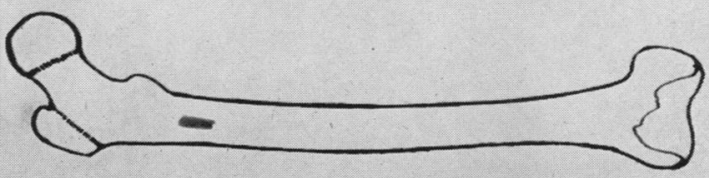

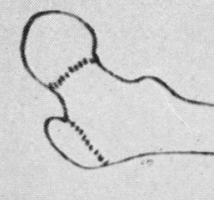
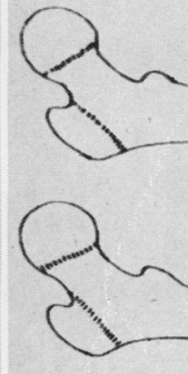

S: $=$

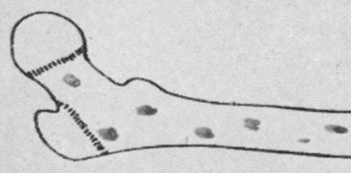

$3=$
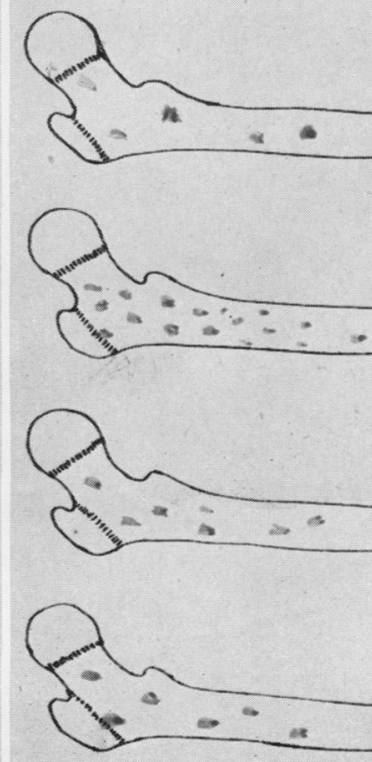
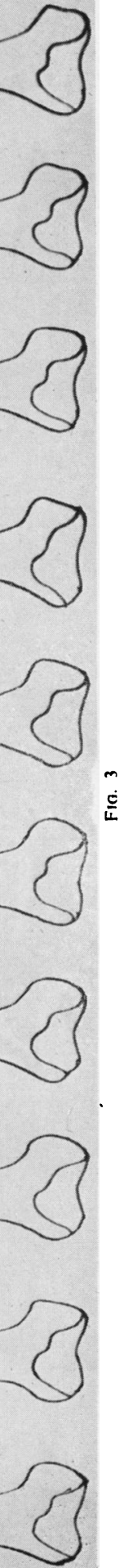
$\frac{1}{4}$

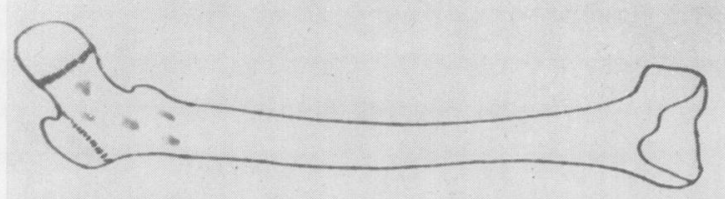

\&-:

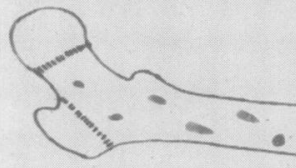

\section{(}
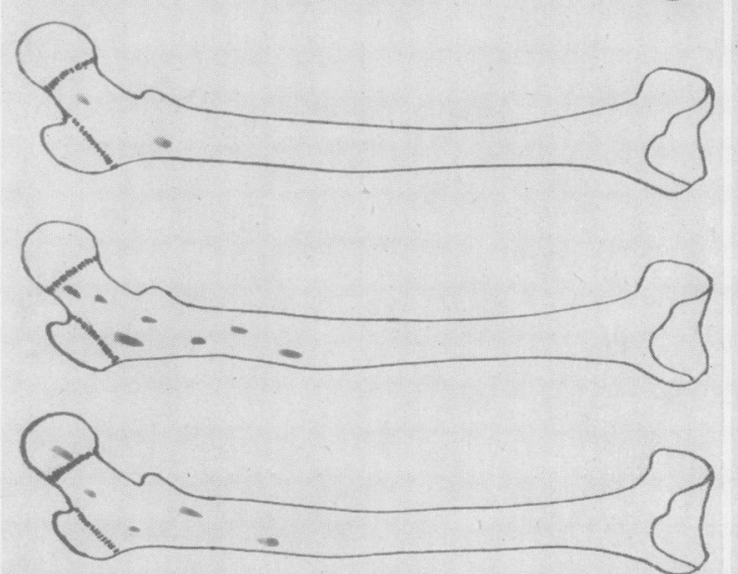

Q

$5=$

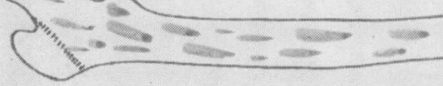

$3_{n-\ldots}$
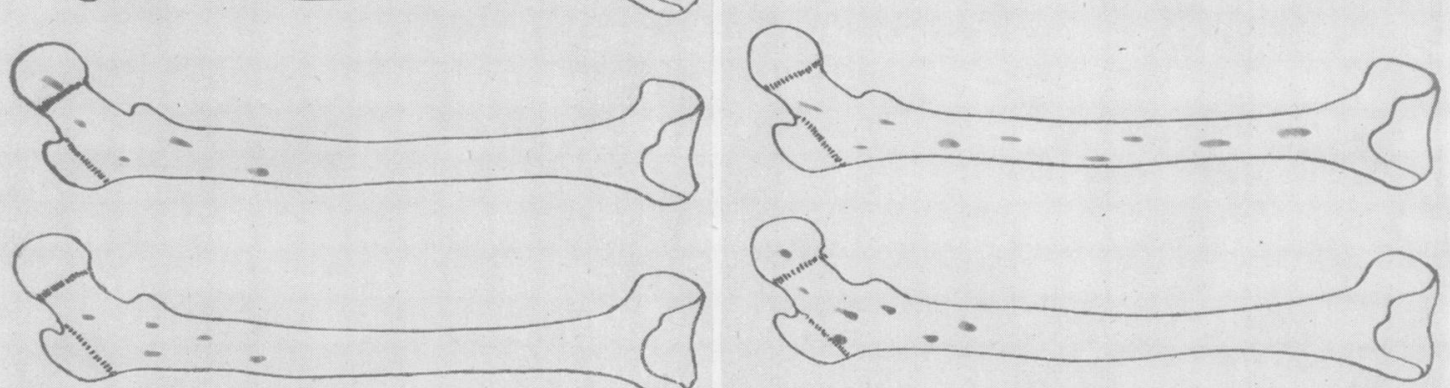

$\sum_{3}$

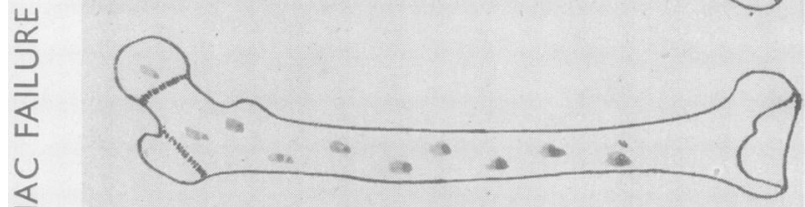

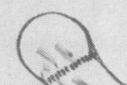

$5-2=-2$

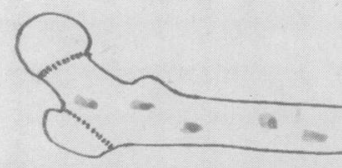

3

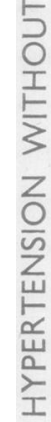

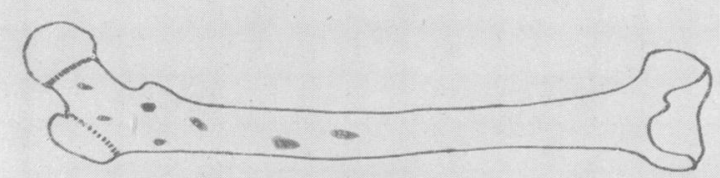

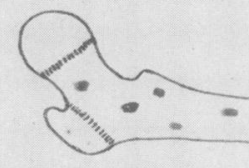

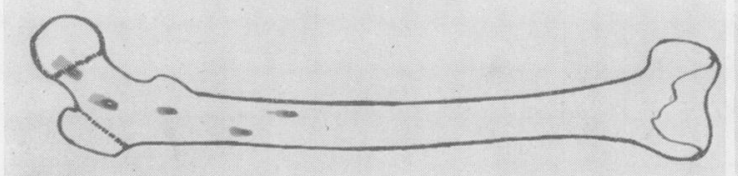

$3=$

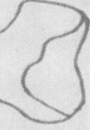

$\iint_{\substack{3 \\ 0}}^{\frac{3}{0}}$

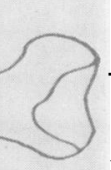

을 
.
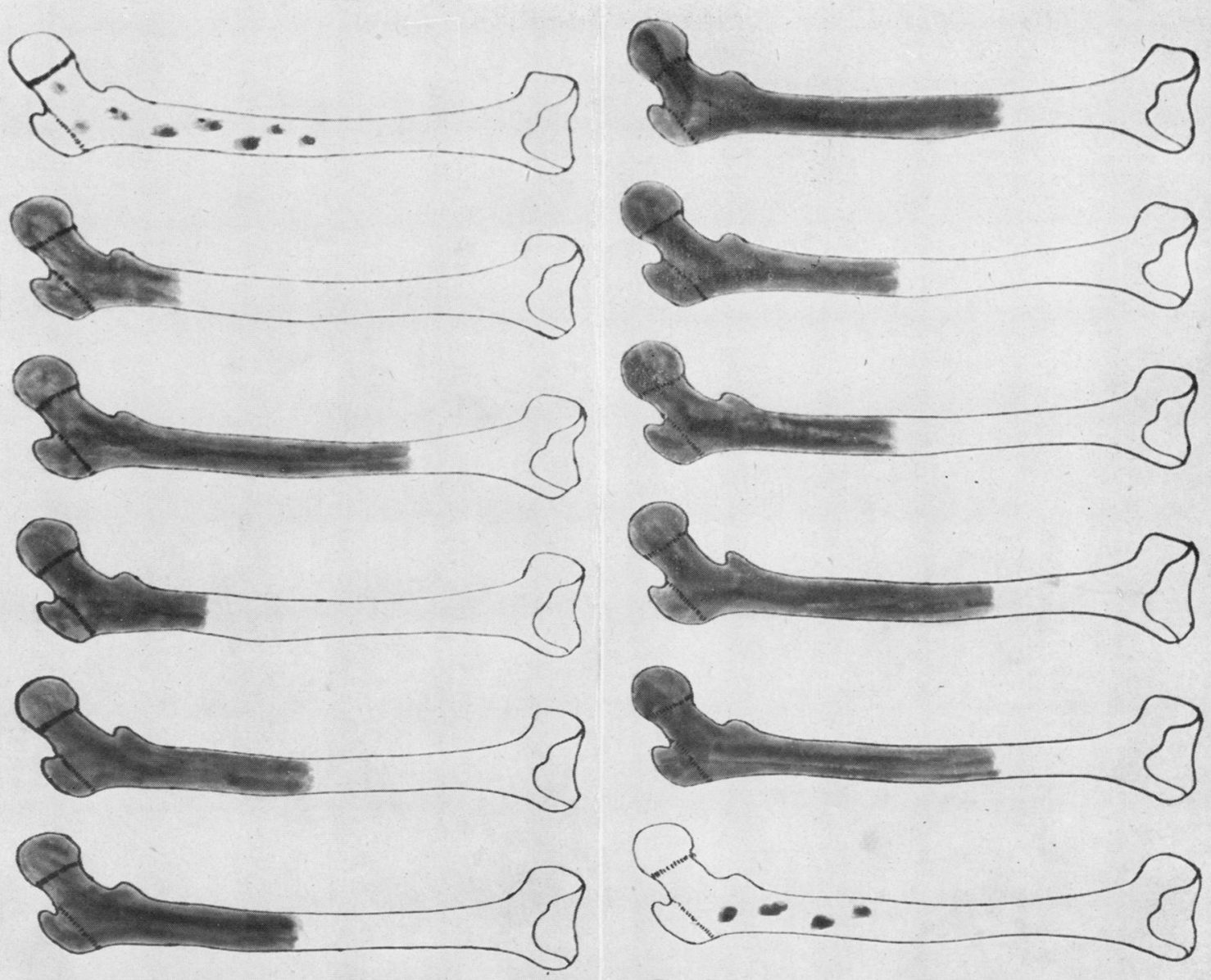

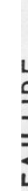
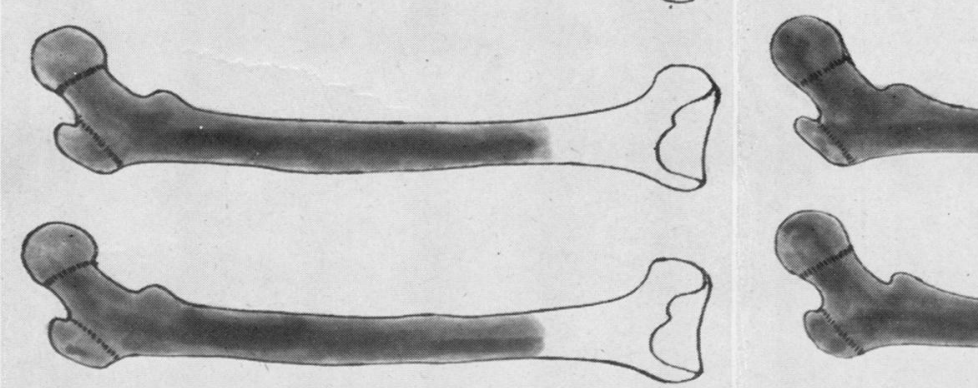

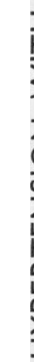
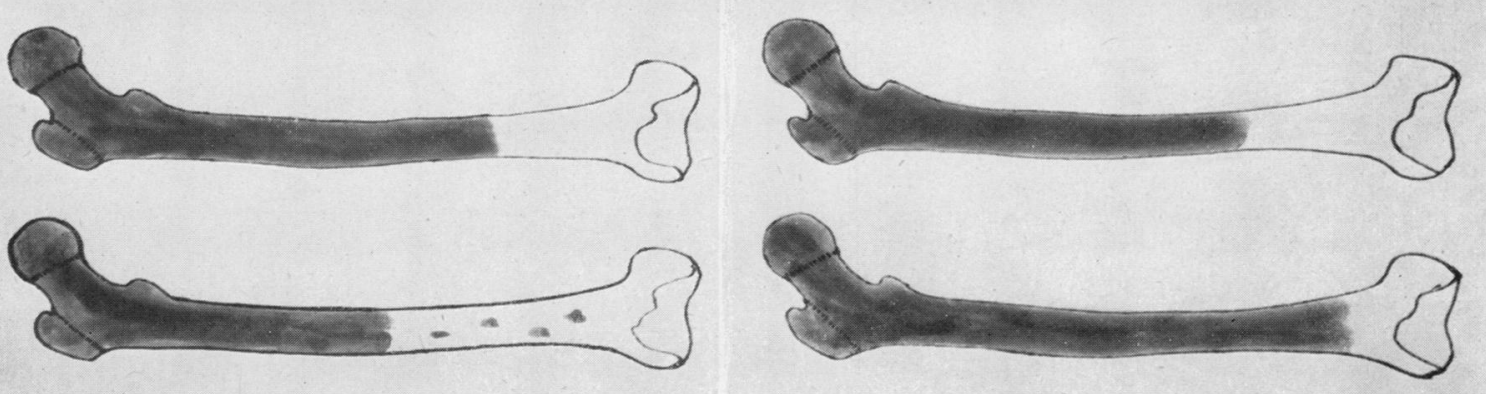

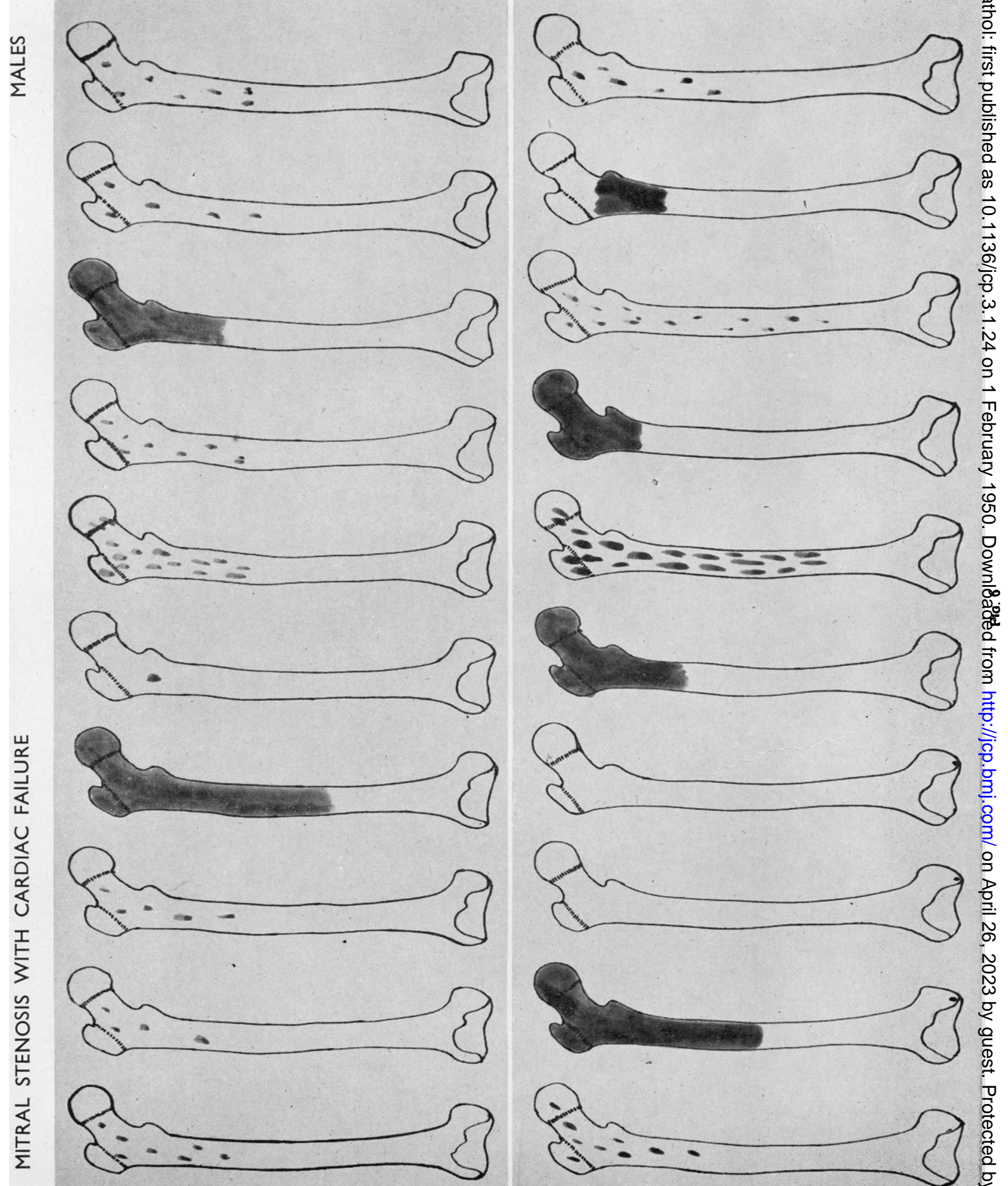
.
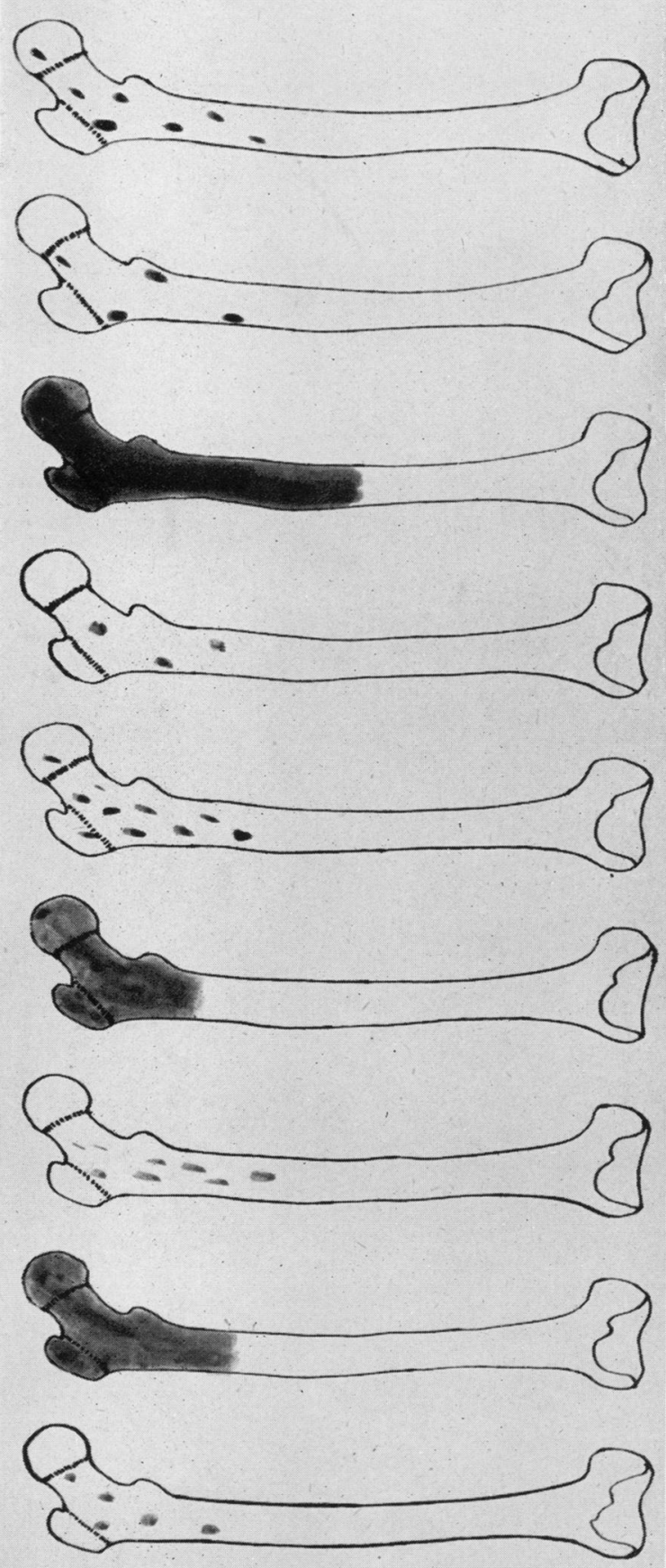

$\delta= \pm=-\cdots$

$\hat{S}_{0}=-$
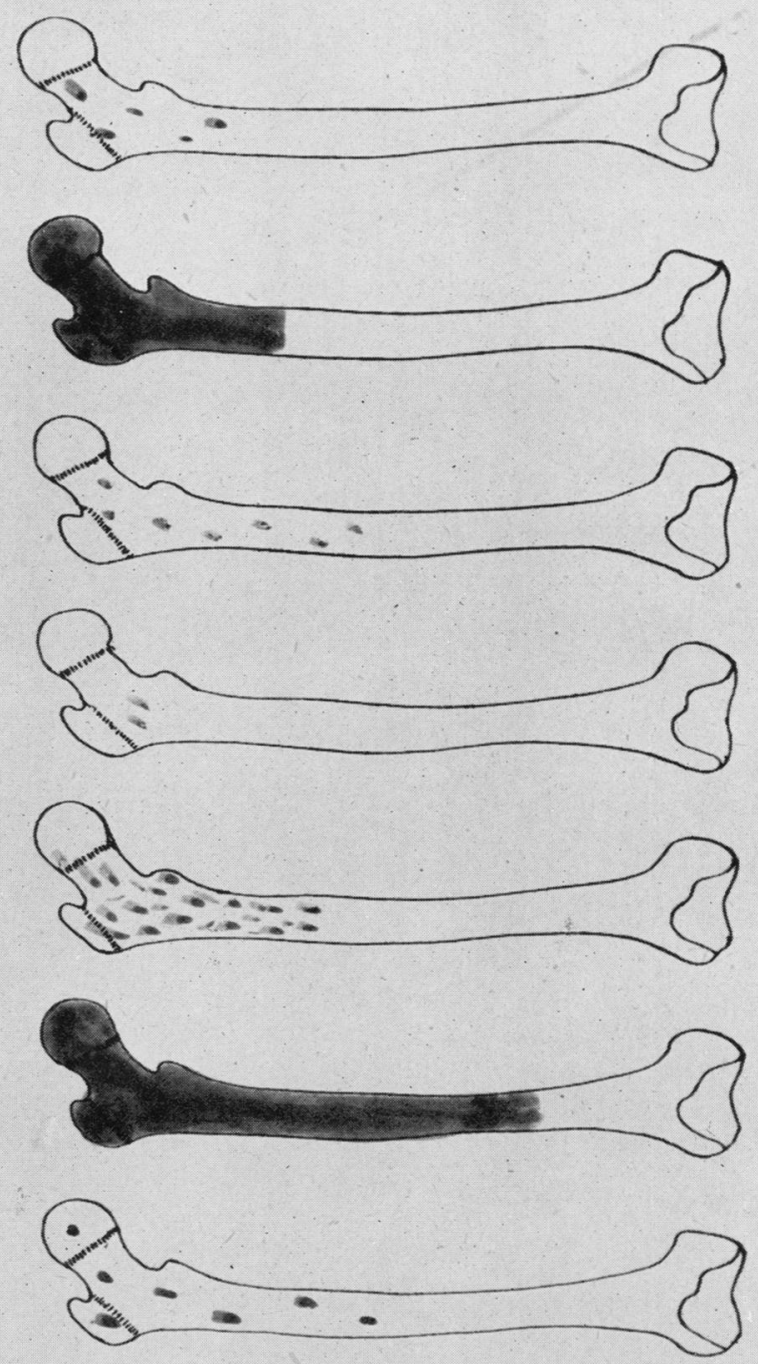

ns

응

음

음

홍

롬

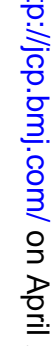

ก

กิ

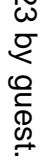

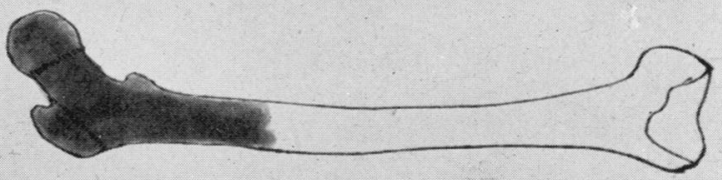




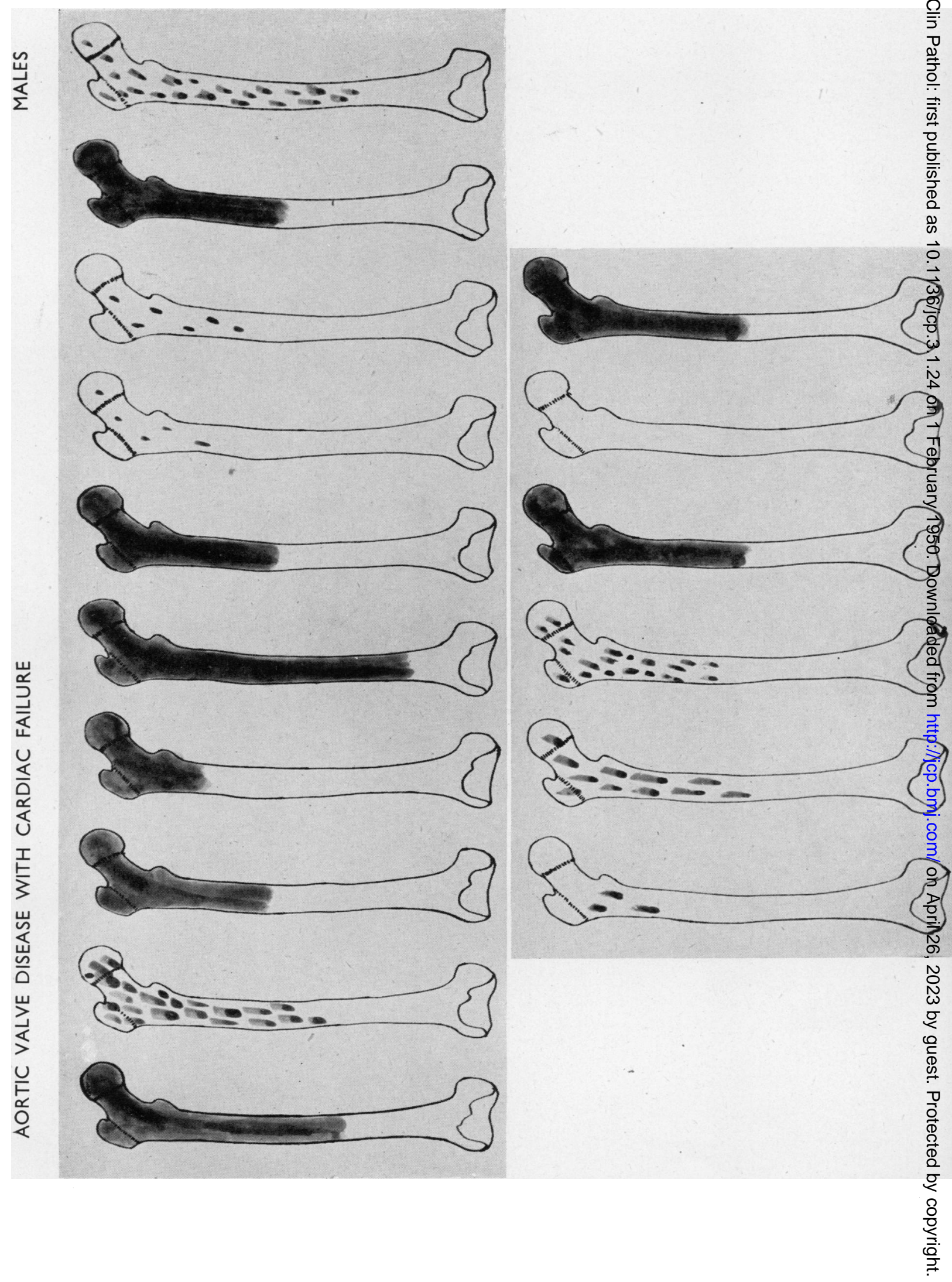




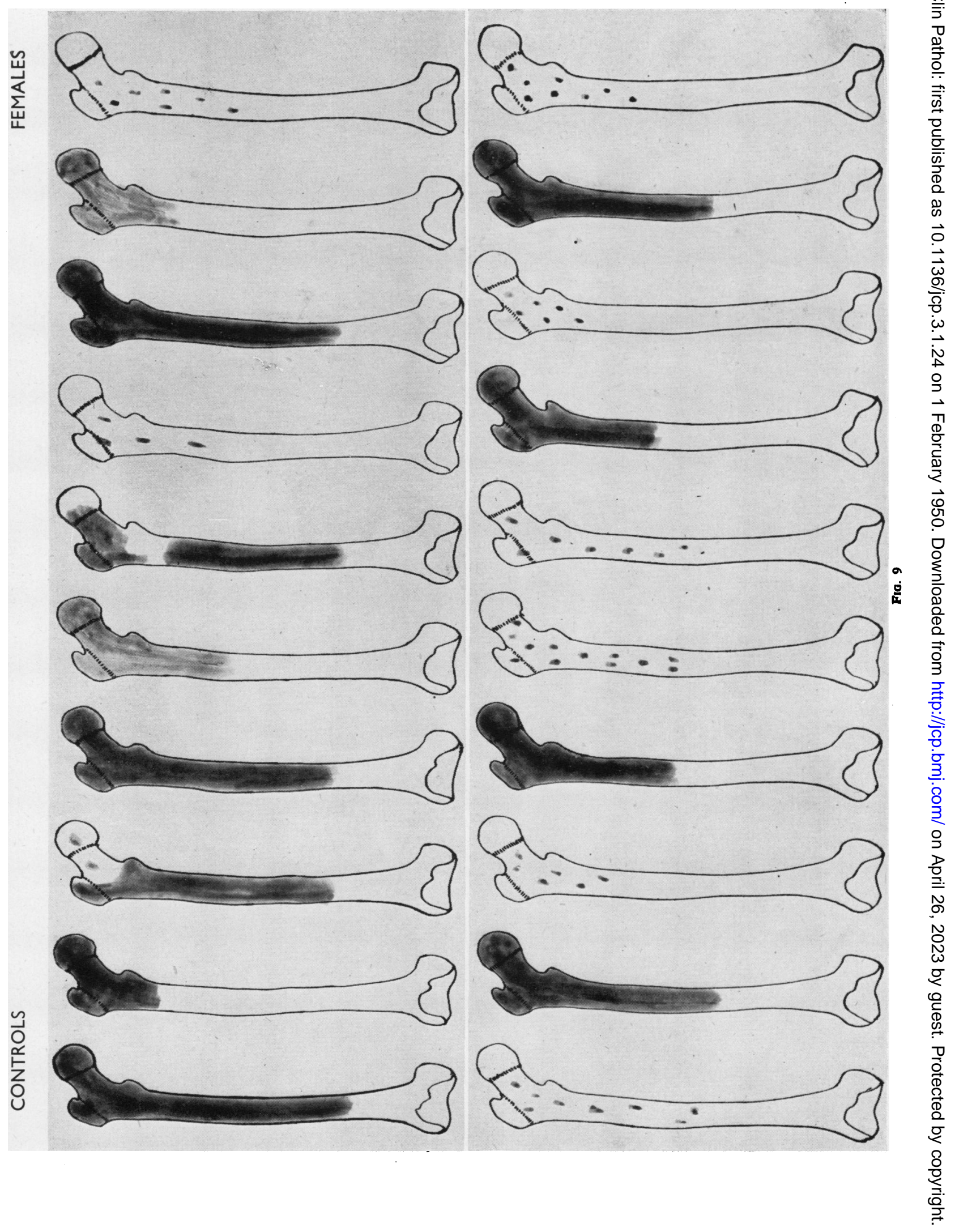


$\frac{\sqrt{u}}{\frac{1}{4}}$
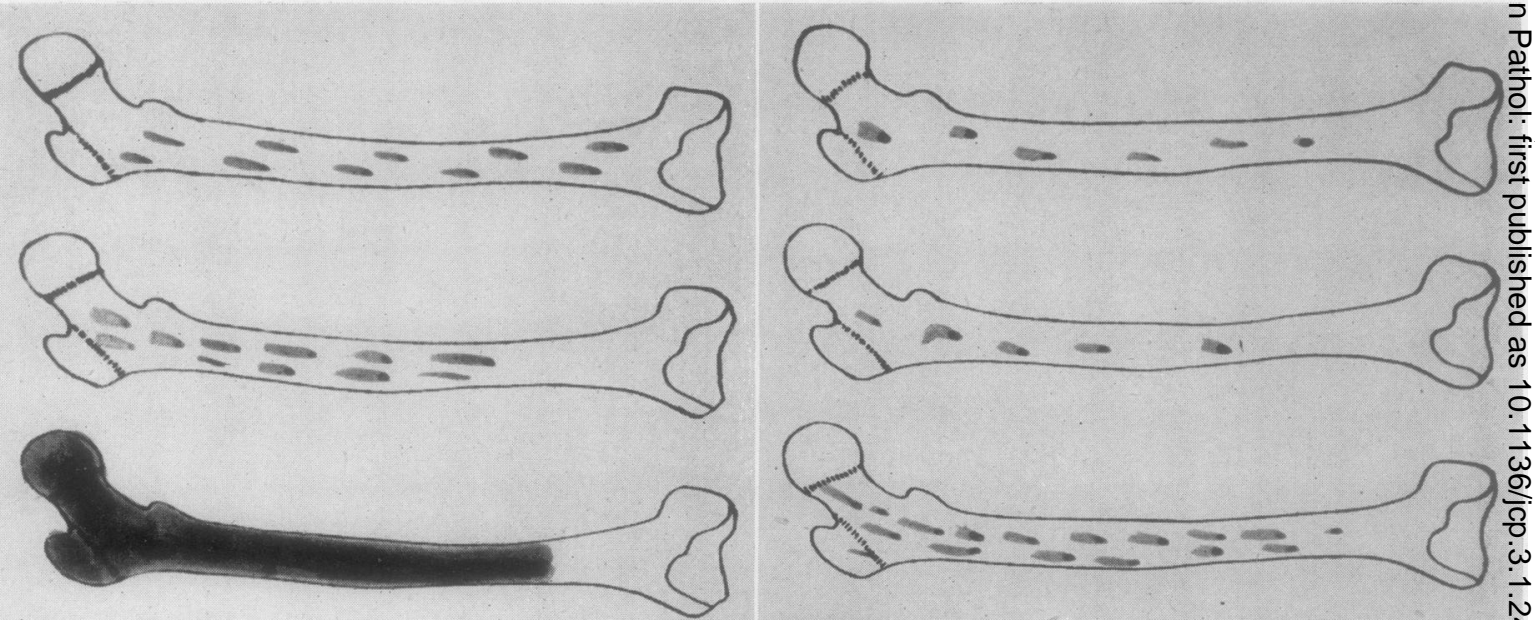

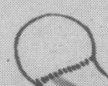
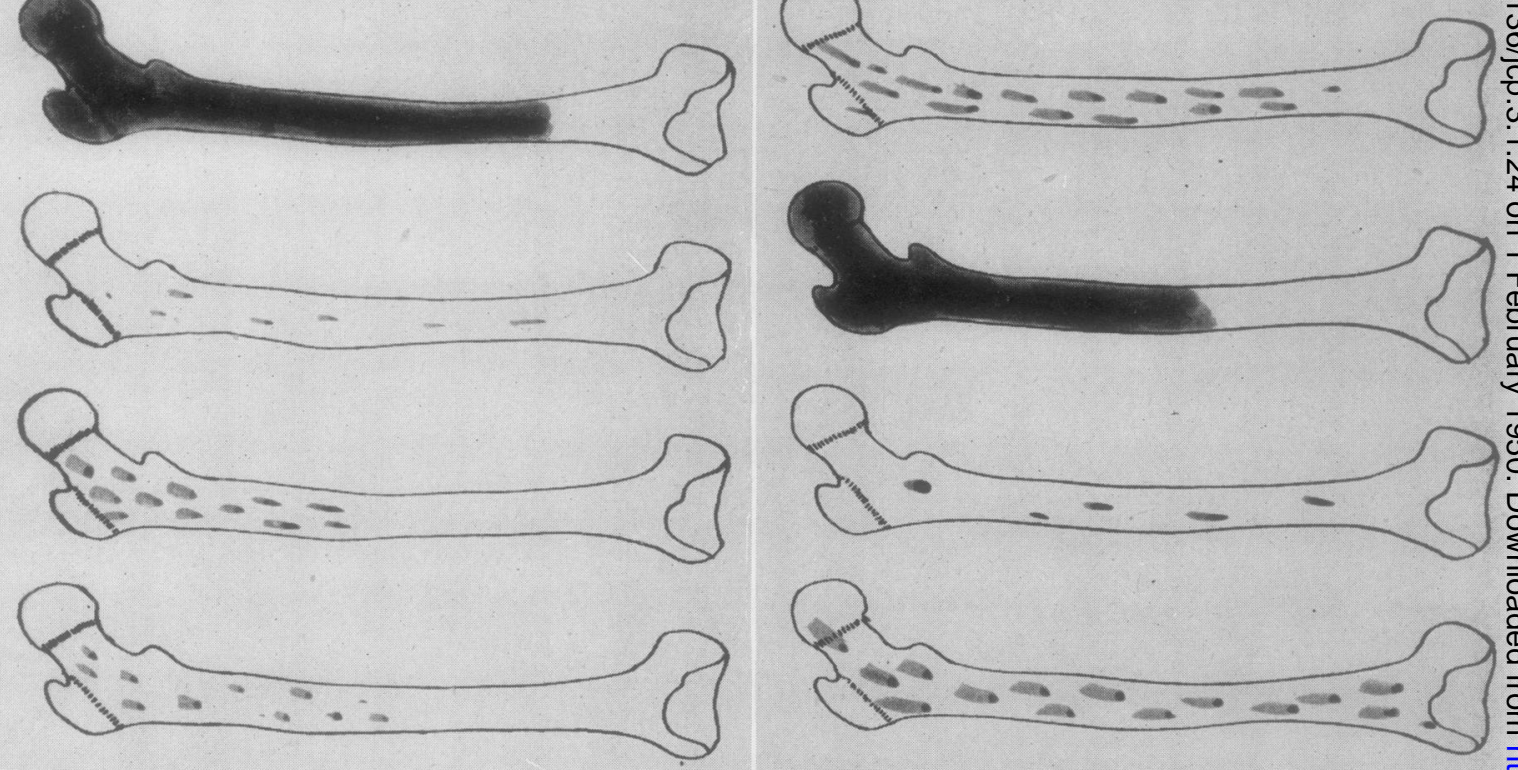

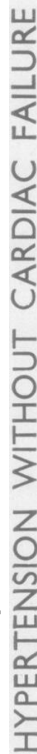
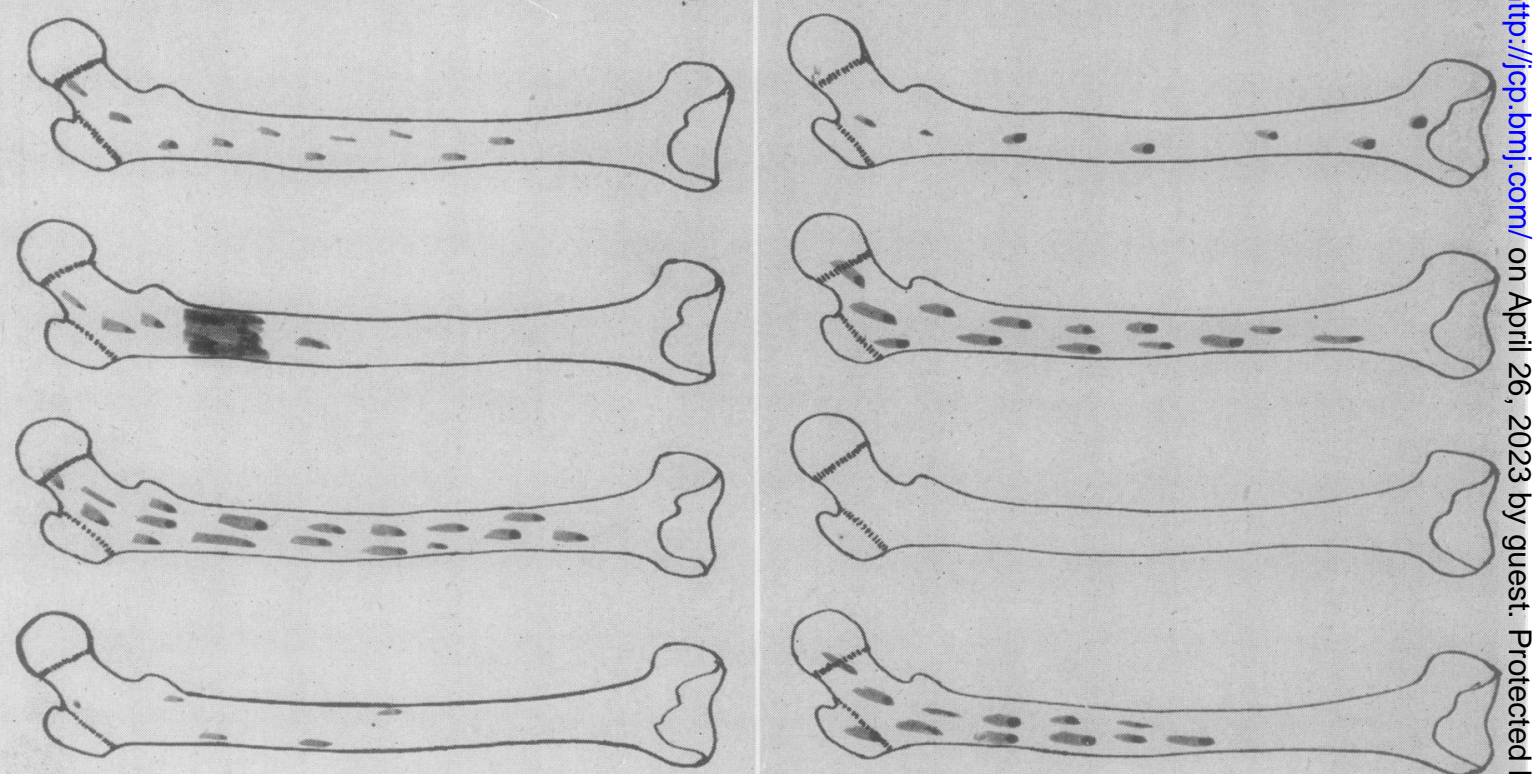


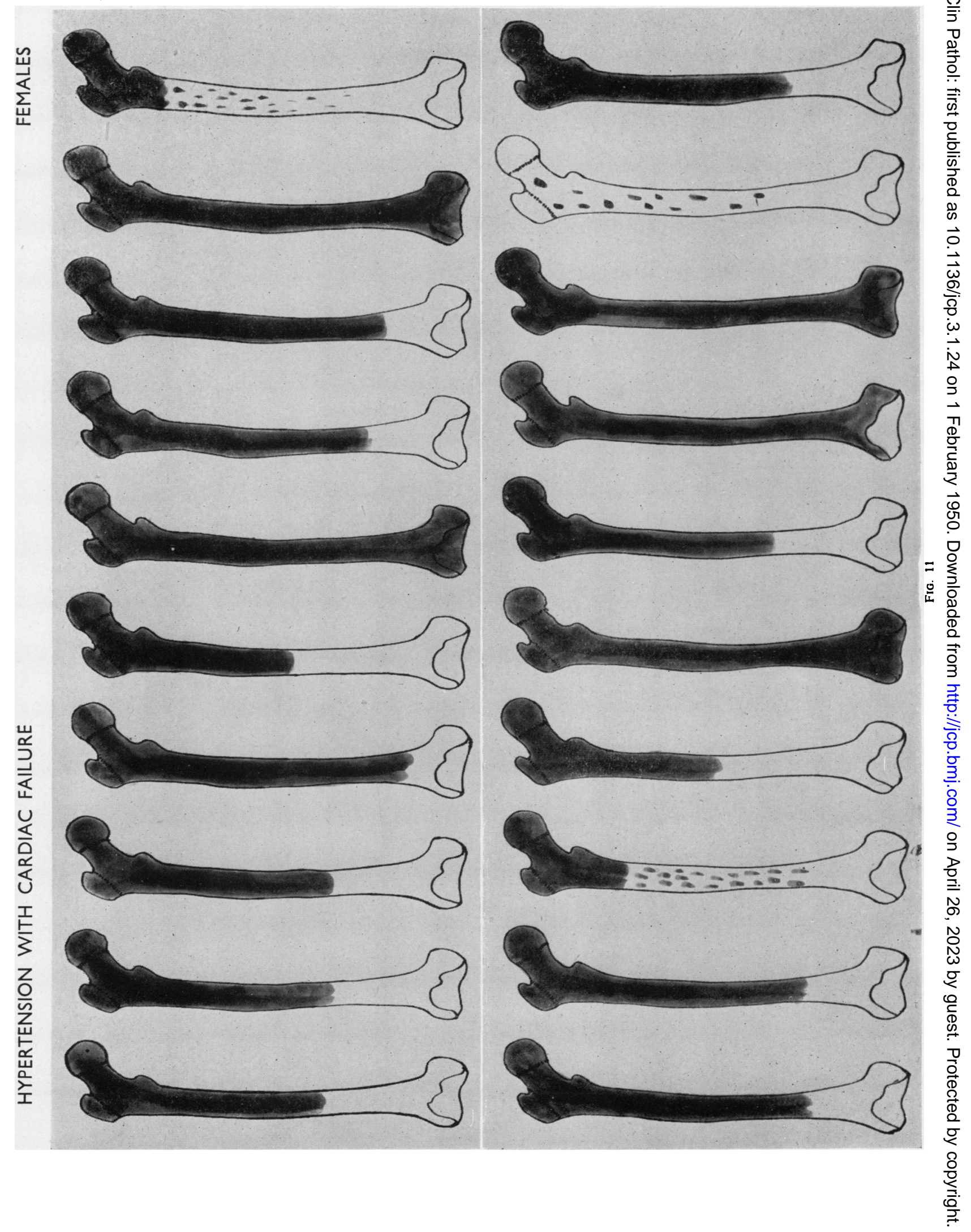




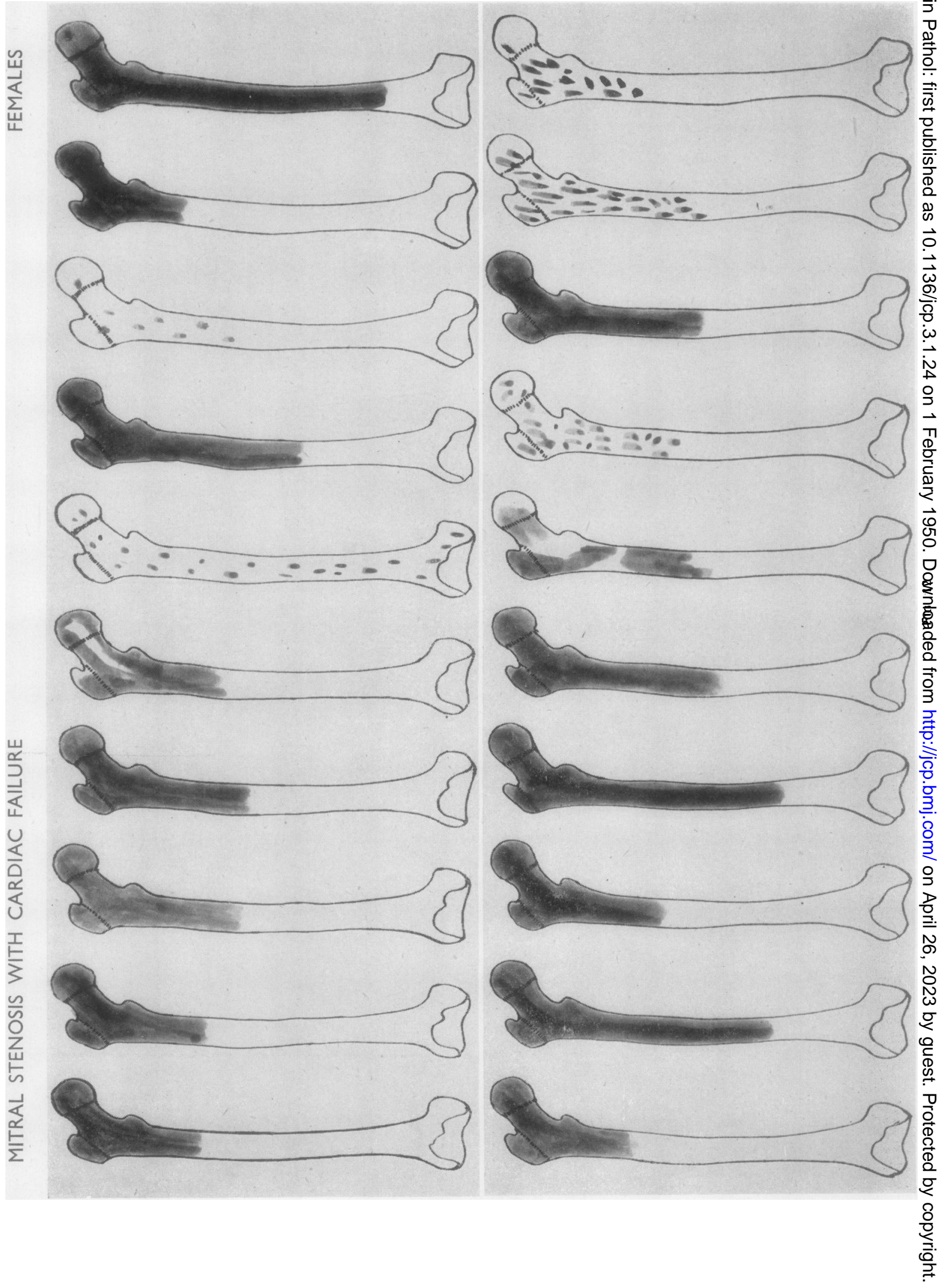


崫
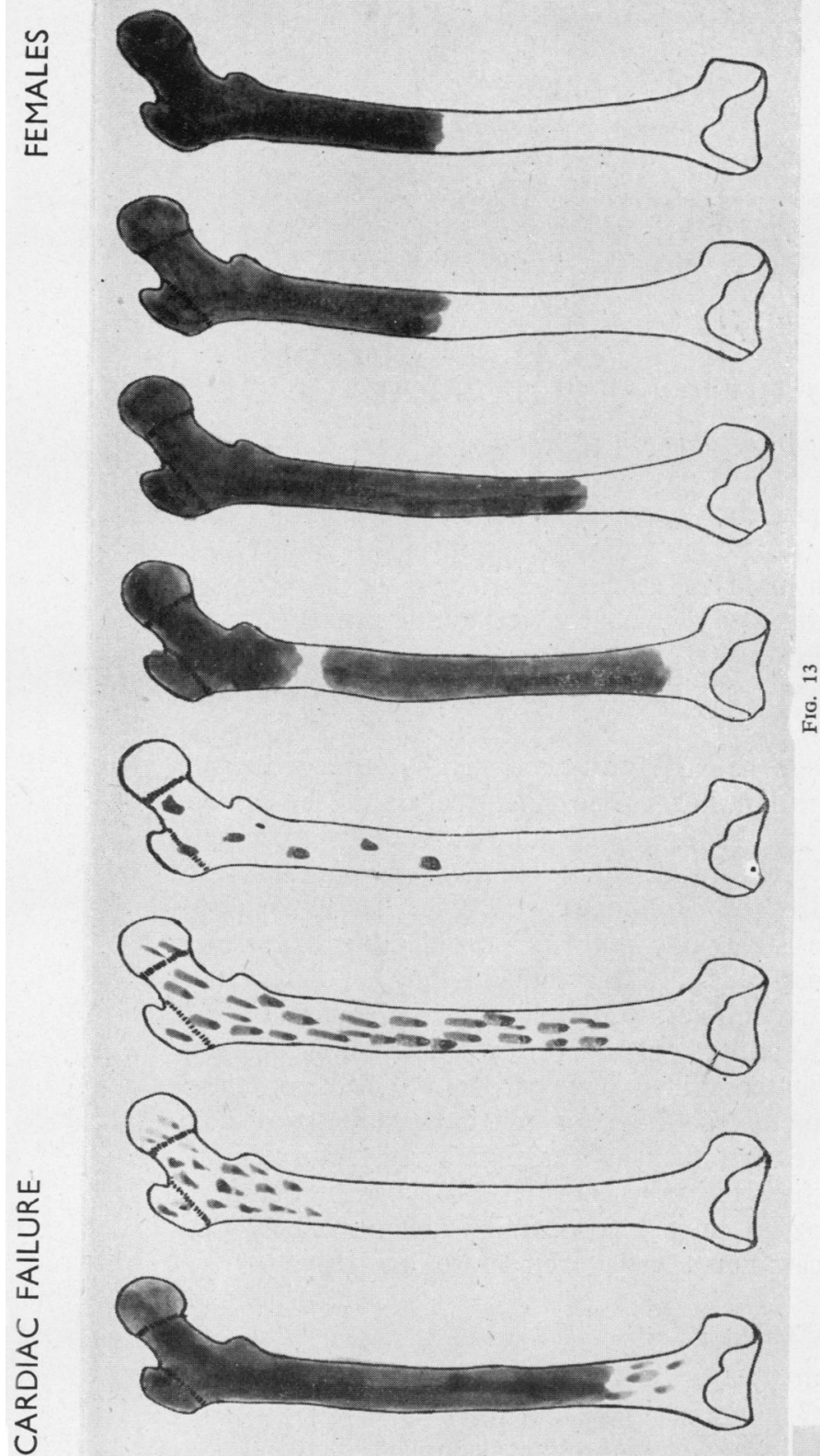

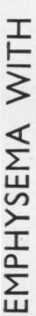
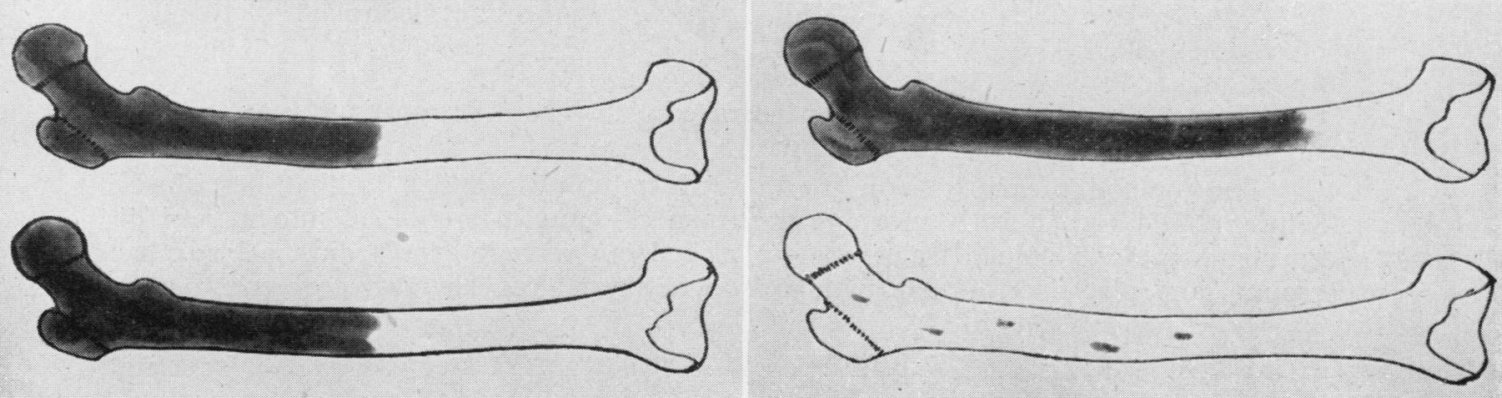